\title{
A escolha e o reconhecimento pela educação: o caso de Antônio
}

Maria da Graça Jacintho Setton'

\section{Resumo}

0 artigo sistematiza ganhos teóricos e metodológicos do uso da noção híbridas disposições de habitus a partir de um estudo de caso. Para desenvolver o argumento, considera primeiramente que a escolha pelo projeto escolar, em função da conquista de um reconhecimento social, pode auxiliar na explanação do princípio hierárquico da construção de um híbrido sistema orientador de conduta. A análise permite observar que o biografado pouco a pouco traça sua singularidade fundindo disposições variadas, entre elas a submissão moral proveniente do trabalho braçal, bem como disposições intelectuais e cognitivas provenientes da escola. Injunções históricas e específicas chances de escolarização foram capturadas e apropriadas por ele num jogo e uso singulares do saber difuso disponibilizado pela frequência a vários círculos sociais. Apontando aspectos do comportamento em várias dimensões de sua vida, como práticas éticas, estéticas, religiosas e profissionais, é possível considerar uma articulação singular de disposições de cultura. Por fim, a reflexão permite identificar as relações indissociáveis entre contexto socializador e processos de individuação, na medida em que condições de socialização específicas são capazes de instrumentalizar a composição singular dos indivíduos.

\section{Palavras-chave}

Socialização - Individuação - Disposições híbridas de habitus.

I- Universidade de São Paulo, São Paulo, 


\title{
Choice and recognition through education: Antonio's case
}

Maria da Graça Jacintho Setton'

\begin{abstract}
This article systematizes theoretical and methodological gains of the use of the notion of hybrid dispositions of habitus by means of a case study. Firstly, in order to develop the argument, it has considered that the choice of the school project, aiming at achieving social recognition, can support the explain the hierarchical principle of the construction of a hybrid system which guides conduct. In the analysis, it is possible to observe that Antonio little by little constructs his singularity amalgamating various dispositions, including the moral submission from manual work as well as intellectual and cognitive dispositions from school. He seized and appropriated historical injunctions and specific chances of schooling in a singular interplay and use of the diffuse knowledge available in the various social circles he takes part in. Pointing aspects of his behavior in different dimensions of life, as ethical, esthetical, religious, and professional practices, makes it possible to consider a singular link of cultural dispositions. To sum up, the reflection allows identifying the inseparable relations between the socializing context and individuation processes, since specific socializing conditions are capable of equipping the singular composition of individuals.
\end{abstract}

\section{Keywords}

Socialization - Individuation - Hybrid dispositions of habitus.

I- Universidade de São Paulo, São Paulo,

SP, Brasil.

Contact: gracaset@usp.br 


\section{Introdução}

Esta reflexão ${ }^{1}$ tem como intenção circunscrever aspectos teóricos e empíricos de análises cujo fundamento é a construção de híbridas disposições de habitus. Num exercício de síntese, a partir de um caso biográfico, busca-se uma interpretação que auxilie a compreensão relacional do fenômeno da socialização e da individuação, oferecendo um instrumental para explanações acerca das relações dialéticas entre indivíduo e sociedade.

É intenção, ainda, explicitar algumas considerações acerca dos processos de socialização atuais, a fim de dialogar com a teoria do habitus de Pierre Bourdieu. 0 intuito é apontar a possibilidade de um sistema de disposições de cultura sui generis, sistema esse de disposições híbrido, construído e adaptado segundo o princípio da fusão, da articulação, pois condições específicas de socialização assim o permitiram.

Identificando uma nova estruturação nos processos de construção dos indivíduos, procura-se uma perspectiva relacional de análise entre instâncias socializadoras, a fim de apreender a especificidade do processo de constituição das disposições de cultura em contexto específicos. Partindo do conceito de hibridismo, do antropólogo Nestor GarciaCanclini (1997), defende-se a hipótese de que a cultura da modernidade imprime uma nova prática socializadora, prática essa distinta das demais verificadas historicamente.

Concordando com Garcia-Canclini, "entendoporhibridaciónprocesossocioculturales en los que estructuras o prácticas discretas,

1- A discussão baseia-se em uma pesquisa mais ampla realizada no âmbito da Faculdade de Educação da Universidade de São Paulo (USP), de um pós-doutorado na Universidade Estadual de Campinas (UNICAMP) e um estágio na Universidade Paris-Descartes, entre 2011 a 2013, com auxílio da Fundação de Amparo à Pesquisa do Estado de São Paulo (FAPESP). Trata-se de uma reflexão teórica, ilustrada por um estudo de caso. Depois de desenvolver uma investigação a partir da perspectiva grupal e ter observado a presença de híbridas disposições de habitus entre os jovens da Amazônia (SETTON, 2012), procurou-se colocar à prova a articulação heterogênea de disposições de cultura em um caso individual. A pesquisa foi realizada em 2012 e 2013, a partir de entrevistas em profundidade, além de observações e visitas locais de 2007 a 2013. que exístian en forma separada, se combinan para generar nuevas estructuras, objetos y prácticas" (GARCIA-CANCLINI, 2000, p. 2). Sem planejamento, como resultado imprevisto de movimentos migratórios, turísticos ou de intercâmbio econômico ou comunicacional, a hibridação de culturas constitui-se em um processo dinâmico, fragmentado, no entanto, também criativo, individual e coletivo, porém, simultaneamente, contraditório e tenso, pois resulta do enfrentamento de valores culturais dispostos em uma hierarquia de poder e privilégios. 0 conceito de hibridação também possibilita entender, entre outros aspectos, como indivíduos se desprendem da força do grupo doméstico, como planejam suas vidas num futuro próximo e como interagem no campo complexo das hierarquias do consumo cultural legítimo e ilegítimo. Considera-se que a modernidade se constitui em um ambiente no qual, indivíduos encontram condições de forjarem um conjunto híbrido de referências disposicionais, mesclando influências em um sistema de esquemas coerente, ainda que heterogêneo (SETTON, 2012).

Por fim, esta reflexão tem a intenção ainda de dialogar com parte das recentes sociologias do indivíduo, mais propriamente a teoria disposicionalista de Bernard Lahire (2004a) e a sociologia das individuação de Danilo Martuccelli (2007). Num exercício de melhor circunscrever a sociedade, numa espécie de sociologia histórica, Danilo Martuccelli (2007, 2010), (SETTON; SPOSITO, 2013) alertam para as transformações estruturais e institucionais vividas na contemporaneidade; para ele, se as análises sociológicas se deparam com a não correspondência entre trajetória social, processos coletivos e experiência individual, deve-se partir para outra inflexão analítica, ocupando-se dos processos estruturais de construção dos indivíduos. Para o autor, os indivíduos não cessam de singularizar-se para além de suas características posicionais.

A presente sistematização propõe, pois, a possibilidade de articular pontos de 
vista epistemológicos, um olhar relacional entre inflexões analíticas de ordem grupal e individual, na tentativa de sugerir uma leitura mais ampla dos processos formativos atuais. Estudos recentes (SETTON, 2014; REIS, 2014; DAYRELL, 2014; ARNOLDI, 2014; GOMES, 2010) servem de apoio a esta discussão, na medida em que evidenciam em experiências biográfıcas ou grupais a necessidade de se articular diversos valores societários em busca do reconhecimento e segurança social.

\section{A perspectiva estrutural, sistêmica, contudo dialética, de Pierre Bourdieu}

Concebendo a sociedade ocidental como uma sociedade hierarquizada, organizada segundo uma divisão de poderes extremamente desigual, a perspectiva bourdieusiana compreende o social de maneira relacional e sistêmica. Para apreender as interações objetivas e verticais entre os indivíduos, seria preciso observar, diacrônica e sincronicamente, as posições que os grupos sociais ocupam segundo uma distribuição de recursos acumulados em suas diferentes trajetórias de socialização.

A família e a escola seriam espaços produtores desses recursos, valores morais e identitários, por excelência extensões formadoras da consciência, matrizes socializadoras responsáveis por um conjunto de experiências, disposições e práticas de cultura. Ambas seriam capazes de tecer, em tensas e intensas relações, disposições de habitus, um modus operandi de pensamento, além de um sistema de disposições que orientaria as escolhas de uma variedade infınita de práticas de cultura. Nesse sentido, a noção de habitus ocupa uma posição estratégica na teoria sociológica de Bourdieu (1979), na medida em que possibilita articular: a) influências externas de socialização (origem social); b) influências conjunturais na composição e formação cultural dos indivíduos; e c) a construção de suas subjetividades. 0 habitus emerge como um conceito capaz de conciliar a oposição entre a realidade exterior e as realidades individuais; é instrumento conceitual que expressa o diálogo, a troca constante e recíproca, entre o mundo objetivo e o mundo subjetivo das individualidades. Ao fugir dos determinismos das práticas, Bourdieu pressupõe uma relação dialética, portanto não linear, entre sujeito e sociedade, uma relação de mão dupla entre habitus individual e a estrutura de um campo, socialmente determinado. Sob essa ótica, as ações, escolhas ou aspirações individuais, a escolha do projeto escolar, por exemplo, não derivam apenas de cálculos ou planejamentos: são, antes de tudo e também, produtos da relação entre as disposições de habitus e as pressões e estímulos de uma configuração histórica e familiar dada aos e subjetivamente apropriada pelos agentes ${ }^{2}$.

Todavia, em condição de modernidade, é imperativo pensar o habitus individual ou de grupos formulado com base em referências diferenciadas entre si. No que se refere ao universo das práticas culturais atuais, constantemente regido por diferentes temporalidades e por distintas orientações, as disposições de habitus devem ser pensadas num processo simultâneo e sucessivo de uma pluralidade de estímulos e referências não homogêneas, não necessariamente coerentes. A opção por este ou aquele gênero musical, ou prática de lazer, por exemplo, expressam, muitas vezes, de maneira modelar a condição de um modo particular de se socializar. Nesse sentido, tudo leva a crer que as disposições de habitus podem ser fundadas em categorias de percepção, apropriação e ação híbridas, que tenderiam a ser acionadas conforme os contextos de sua produção e realização ${ }^{3}$.

\footnotetext{
2- Para uma discussão mais detalhada sobre esse aspecto, consultar Setton (2002, 2009a, 2012).

3- "Vou dissipar outra dificuldade: o habitus, por ser um sistema de virtualidade - só se revela em referência a uma situação. Contrariamente às afirmações que me são atribuídas, é na relação com determinada situação que o habitus produz algo. Ele é semelhante a uma mola, mas é necessário um desencadeador; e, dependendo da situação, ele pode fazer coisas opostas." (BOURDIEU; CHARTIER, 2011, p. 62).
} 
Nessa linha de discussão, destacase Bernard Lahire (2004a, 2004b, 2006). Segundo ele, a coerência dos esquemas de ação ou as disposições de cultura que os atores interiorizam dependem notadamente da coerência dos princípios de socialização aos quais estão submetidos. Como desdobramento desse raciocínio, para Lahire, a incoerência das disposições de cultura impediria o uso do conceito de habitus, pois este é formulado a partir do princípio da unidade. Contudo, ao contrário e diferente deste autor, considerase que o conceito de habitus continua sendo um instrumento de análise relevante para se compreender os processos socializadores atuais, dado que permite observar as texturas sociais diferenciadas, ora coerentes ora heterogêneas, enquanto formas de organização e/ou significação de condutas (MARTUCCELLI, 2010, p. 222; SETTON, 2012).

Habitus é mediação que se constrói processualmente, em muitos momentos da trajetória dos sujeitos; um conjunto de experiências acumuladas e interiorizadas, passíveis de se modificarem e de se realizarem como respostas aos momentos de necessidade. Como diria Bourdieu (1998, p. 54), "como não ver que o grau em que um habitus é sistemático (ou, pelo contrário, dividido, contraditório), constante (ou flutuante ou variável), depende das condições sociais da sua formação e do seu exercício, e que pode e deve, portanto, ser medido e explicado empiricamente?" 0 princípio de unicidade dos habitus, pois, na contemporaneidade, seria a capacidade de mesclar disposições de cultura. Dessa forma, o habitus pode ser construído por disposições híbridas, desde que as condições de socialização assim o determinem. Ou mais, traçada em contextos societários em que a coexistência de múltiplas referências e orientações de valores é constitutiva de uma história, a hibridação de comportamentos deve ser vista como uma possibilidade teórica e simultaneamente histórica. Não seria somente uma socialização plural, pois essa infere uma vocação sincrônica relacionada a uma diferenciação social e de grupo. A socialização híbrida, por outro lado, sem negar a dimensão precedente, está ligada a uma diacronia, pois o diferencial das socializações integra elementos que pertencem a representações históricas individualmente percebidas. Ou seja, uma socialização diacrônica, na medida em que os indivíduos combinam elementos que, segundo representações sociais, pertencem a diferentes momentos históricos, por vezes, modernos e tradicionais, seculares ou religiosos, todos dependentes de uma hierarquia de valores. Assim sendo, a noção de socialização híbrida serviria como um operador analítico para sociedades que passam por expressivos processos de modernização $0^{4}$.

Ademais, ao pensar a articulação de um conjunto de disposições híbridas na origem das praticas e ações, evidencia-se uma ferramenta conceitual que foge do entendimento da neutralidade dos sincretismos culturais. Historicamente marcado por um imaginário positivo e democrático, o princípio da hibridação aqui utilizado, ao contrário, chama a atenção para as armadilhas hierárquicas que as sociedades multiculturais podem encerrar. A noção de híbridas disposições de habitus é capaz, pois, de revelar que a composição e/ou as escolhas por determinados valores e práticas podem corresponder a uma leitura singular que os sujeitos realizam em situações específicas. 0 princípio de hibridação utilizado obedece a uma percepção de valores e/ou de orientações bem-sucedidos em determinado contexto social; ou melhor, valores que poderiam ser capitalizados a partir do julgamento/avaliação das condições vividas. 0 princípio da hierarquização das disposições de habitus responde, muitas vezes, a valores legitimados ou com maior apelo social, como a educação escolar, por exemplo.

Portanto, a hibridação de disposições não é indiscriminada ou neutra. Não é possível mesclar, fundir nem mesmo escolher práticas

4 - Gostaria de agradecer a Danilo Martuccelli por ter formulado essa proposição de maneira clara, alertando para o fato de que uma socialização híbrida responde notadamente a diferentes temporalidades históricas. 
arbitrariamente. As opções de orientação e de prática que se pode abraçar correspondem a estratégias de aceitação e reconhecimento, respondem a demandas sociais derivadas de uma avaliação sobre a realidade que cerca e constrange os indivíduos. Para se chegar a uma interpretação plausível, crê-se ser capaz assim de alcançar novos processos de coexistência e produção de sentidos; processos realizados pelos sujeitos como estratégias de subjetivação e compreensão de novos signos de identidade e ou individuação (MONTEIRO, 2003, p. 116-118) . $^{5}$

Por fim, a proposta de se pensar as disposições de cultura a partir da categoria híbrido resulta num caminho de se apreender saídas estratégicas, ou até mesmo táticas, para se sobreviver em um mundo pleno de contradições. A proposta de se trazer a noção de hibridação revela uma alternativa de se compreender a ação do agente social a partir de sua percepção acerca de valores hierárquicos no interior de estruturas sociais em transformação. Um esquema interpretativo que explicitaria uma subjetividade em funcionamento; aspectos valorativos motivariam os indivíduos a investirem ou a se afastarem de diferentes experiências ou orientações sociais. A aventura do social, ainda que consolidada, apresenta-se, em parte, maleável pela ação avaliativa dos sujeitos em um determinado espaço-tempo. Em síntese, há uma compreensão sobre a forma como os indivíduos articulam diacronicamente as múltiplas influências sociais a que são submetidos sem hipostasiar e/ou reificar a noção de disposição de cultura, como alertado por Nogueira (2013).

\section{As sociologias do indivíduo: a}

não linearidade das relações indivíduo e sociedade

Corroborando a discussão, relembra-se aqui mais uma vez a contribuição de

5- Nesse sentido, a intenção aqui é aprofundar empiricamente a correspondência entre estruturas sociais/estruturas de socialização e a tessitura da individuação. Não se confunde com a discussão sobre a capacidade de livre-arbítrio dos indivíduos.
Martuccelli (2010). Segundo o autor, a sociologia da individuação permite fazer uma espécie de macrossociologia que parte da vivência individual com vistas a chegar ao comum de cada sociedade, por exemplo, o desafio da escolarização. Fazendo ponderações críticas acerca do conceito de socialização clássico e dos autores que observam os processos de individualização unicamente a partir do enfoque institucional, Martuccelli interpela a experiência do ator social que, pouco a pouco, tem se realizado por fora, contra ou diferente das instituições. Para Martuccelli, entre outros autores, já há algum tempo, a crise da sociologia tem se desenhado em função da dificuldade de ajustar linearmente experiências individuais e processos estruturais. Para esses estudos, na modernidade tardia, a partir de meados do século passado, a diferenciação social, a pluralidade dos círculos sociais (ARNOLDI, 2014) e a dinâmica experiência urbana (REIS, 2014) impõem novas formas de socializar os indivíduos.

Por razões de ordem histórica e teórica, é mister compreender que embora os percursos individuais atravessam contingências posicionais (SETTON, 2014), de gênero (GOMES, 2010), especificidades geracionais (DAYRELL, 2014) ou de nacionalidade, submetem-se sobremaneira a uma deriva, a um processo histórico contingente e maleável. É preciso, portanto, que investigadores examinem de perto as circunstâncias, a rede de relacionamentos e a configuração societária responsáveis pela sustentação dos processos de transmissão, incorporação e legitimação de valores culturais; nesse sentido, é necessário ainda recortar uma situação histórica, social e ou mesmo familiar de interiorização do social objetivado, na tentativa de compreender a correspondência entre processos socializadores e de individuação.

Isto é, se a tarefa da sociologia sempre foi, independentemente das escolas sociológicas, foi compreender as experiências pessoais a partir de lógicas grupais e societárias, é preciso hoje admitir novos recortes. 0 antigo modelo interpretativo tem apresentado dificuldades, 
na medida em que a noção de uma sociedade integrada desfaz-se com o surgimento de vivências contingentes e incertas. Não se trata de romper com uma leitura posicional, segundo Martuccelli; trata-se de uma necessidade epistemológica de se compreender as incertezas de um mundo atravessado por uma variedade de orientações em constante disputa. Os indivíduos não seriam efeitos diretos das circunstâncias econômicas, políticas ou sóciohistóricas. Estas devem ser vistas como um espaço de um jogo cuja elasticidade obriga a reconhecer e considerar o trabalho que os indivíduos desenvolvem sobre si.

De acordo com Martuccelli (2007), o espaço das escolhas individuais, como, por exemplo, a valorização da escolarização ou o seu inverso, é dado pelas texturas, pelas consistências sociais, isto é, os agentes fazem uso de soluções biográficas no interior das contradições sistêmicas. Os indivíduos não são mais obrigados a se espelhar nas autoridades (familiar e escolar); ao contrário, podem estabelecer comportamentos menos obedientes e mais reflexivos frente às dificuldades que encontram ao longo de suas experiências socializadoras. Posto isto, a sociologia da individuação serviria como uma alternativa complementar de interpretação da realidade social, a qual interroga sobre o tipo de indivíduo estruturalmente produzido por uma sociedade em um período histórico. Perscrutando o trabalho que indivíduos fazem consigo mesmo, pode-se observar respostas singulares a dificuldades comuns, como a escolarização, respostas diferentes que resultam de uma pluralidade de posições, recursos, estratégias e habilidades articuladas.

\section{A busca pelo reconhecimento e a escolha pela educação}

Dando continuidade à discussão acima, a fim de concretizá-la em um caso empírico, nesta seção, enfatizam-se as noções de reconhecimento e escolha como eixos interpretativos de uma trajetória pessoal. Tem-se como base a história de vida de um indivíduo que nasceu, mora e trabalha na e para a sua comunidade, o distrito de Alter do Chão, em Santarém, no estado do Pará. Professor de uma escola local, descendente dos índios Boraris, Antonio ${ }^{6}$ frequentou o mestrado na Universidad de los Pueblos de Europa. Escritor, publicou um livro sobre uma festa regional bastante conhecida, o Çairé, bem como outro relativo à sua cidade natal, tendo recebido por isso prestígio tanto no universo da cultura popular quanto no âmbito da cultura acadêmica. A esse empreendimento, soma-se o empenho na divulgação do ritmo local carimbó, ainda que tenha como preferência pessoal a música eletrônica e o rock progressivo. Sujeito articulado, convive e disputa com autoridades oficiais, midiáticas e locais o projeto educativo do colégio em que leciona. Antonio apresenta também múltiplas facetas: circula na escola, está presente na rádio local, coordena festas populares, é bom articulador político, é professor de língua inglesa e portuguesa - e, nos momentos de necessidade, também professor de religião -, e postula a fé católica, embora em ocasiões especiais recorra aos conselhos da pajelança ou do espiritismo.

Para traçar as correspondências entre a socialização e a tessitura da individuação de Antonio, ou para compreender a correlação entre a busca por um reconhecimento e suas escolhas de formação escolar, poder-se-ia começar pelas representações valorativas acerca das ideias de progresso e desenvolvimento que pairam sobre a região. Sabe-se que essa opção pode soar arbitrária; todavia, ela possibilita circunscrever a narrativa que segue. Convivendo em um ambiente de baixa escolaridade, absorvendo os discursos de atraso sobre a região e sua população de origem, seria esperado de Antônio um esforço objetivo e subjetivo de transformação dessa ordem. Embora em outros núcleos brasileiros o conhecimento escolar já não seja o diferencial

6- 0 nome dado ao sujeito da narrativa é fictício. Vale salientar que se tem permissão de uso de sua história pessoal para fins acadêmicos 
para se alçar a uma mobilidade social, em Santarém, quem conta com um diploma e apresenta um saber diferenciado dos demais torna-se muito valorizado, ou seja, passa a ser notável e notado; passa a ser reconhecido e a se reconhecer como especial. Como diz o ditado, "em terra de cego quem tem olho é rei".

Valeriam alguns apontamentos sobre o que se entende pela noção de reconhecimento, pois ela é uma constante no discurso de Antonio. Embora bastante antiga, a expressão assumiu uma repercussão teórica nos últimos dez anos de maneira bastante singular (HONNETH, 2006; GUÉGUEN; MALOCHET, 2012). A noção de reconhecimento passou a ser objeto de seminários e de reflexões de ordem política e fenomenológica, explicitando um sentimento comum das sociedades modernas, ou seja, a competição e o singularismo. Não obstante, talvez de todo o debate travado até agora, aquele que mais se aproxima das intenções deste texto se refira às reflexões de Axel Honneth (2006), pois esclarece como o espírito de uma época pode dialogar com a formação das representações e maneiras de ser e agir dos sujeitos.

Segundo Honneth (2006), o reconhecimento é um sentimento comum e fundamental na construção identitária. Possui uma dimensão antropológica, pois, como seres humanos, não podemos desenvolver uma identidade e/ou uma relação positiva com o mundo sem que tenhamos vivido experiências positivas sobre ela. Trata-se de uma noção relacional que aborda três eixos fundamentais da existência. Para Honneth (2006), tais eixos podem conviver juntos ou em separado, mas sempre estarão condicionados por um contexto social. Seriam eles o eixo relativo ao: a) princípio do amor ou afeto, construído sobretudo na esfera íntima/familiar; b) princípio da solidariedade, desenvolvido nas relações com a comunidade; e, por fim, c) o princípio da igualdade, encontrado nas relações jurídicas.

Essa síntese, ainda que muito sucinta, é oportuna, pois oferece um caminho para se analisar a experiência de Antonio. Ela auxilia a interpretação da sua busca de visibilidade, aceitação e distinção, a partir de um particular esforço e dedicação aos estudos. Sociologicamente, é compreensível esse empenho por atestar uma compreensão intuitiva dos projetos e/ou estratégias de reprodução ou melhoria de oportunidade do seu grupo de origem. Na ocasião de sua graduação, décadas de 1980 e 1990, os índices de escolarização na região traduzem uma precariedade. Os sopros ou os ciclos de esperança da região amazônica decerto promoveram expectativas maternas aceitas docilmente por Antonio. Desde muito pequeno, o entrevistado manifestou desejo de ser bem avaliado, de ser cumprimentado por seu esforço. 0 ajuste entre o projeto familiar e o projeto de vida pessoal tornou-se factível e desejável para ele. Indo um pouco além, poder-se-ia afirmar ainda que um elemento de natureza subjetiva somou-se, ou melhor, integrou-se a um contexto específico.

De maneira não planejada, Antonio foi matriculado por uma conhecida da família em um curso técnico noturno, na escola privada mais prestigiada do município, onde teve que aprender a conviver com e entre diferentes. Para garantir sua sobrevivência nessa nova etapa da vida, foi obrigado a lançar mão de vários recursos. De certa forma, a faceta de circular por tantas atividades profissionais ou laborais, muitas delas distintas, conferira a ele uma particularidade comum entre trabalhadores da América Latina (MARTUCCELLI, 2010); colecionou aspectos e ou fragmentos de formação, desenvolveu uma série de atividades multideterminadas, ao mesmo tempo em que não se especializou em nenhuma. Antonio, que tanto valoriza a conquista de seus diplomas, revela estar permanentemente em formação, ao abraçar uma variedade de atividades no campo da cultura. Seu percurso favorece a composição, a fusão, uma disposição para enfrentar o novo, a aventura, o imprevisto. E, nessa condição, traça sua sensibilidade e individualidade.

Decerto, o contexto local, as oportunidades que se abriam ou fechavam 
exigiram-lhe uma postura particular de fundir experiências. Tudo leva a crer que circular entre mundos com valores tão diversos permitiu a Antonio traduzir a constituição de um contexto histórico específico. A vida singular desse sujeito pôde pôr em evidência uma condição cultural mais ampla, retratada por um Brasil construído em sua hibridação, na mescla de comportamentos e códigos de vários segmentos sociais. É surpreendente como a vida de Antonio auxilia o circunscrever de um novo modus operandi na constituição de algumas disposições de habitus, isto é, um sistema gerador de maneiras de ser, reagir e imaginar outro mundo para si.

Em outras palavras, poder-se-ia afirmar que, ao articular experiências de vida realizadas na família, na escola, no grupo de pares ou no trabalho, Antonio deu a cada um desses patrimônios um peso específico, segundo sua sensibilidade e apreciação $0^{7}$. Assim sendo, seria difícil generalizar à medida que cada um de seus pares daria à arte de articular essas referências. No caso de Antonio, princípios familiares, em parte apropriados, em parte abandonados, segundo uma sensibilidade do momento e, sobretudo, uma avaliação própria, são dinâmicas não verificáveis a priori. Só seu relato permitiu verificar o sentido e a direção dessas articulações. Arriscar-se-ia afırmar, inclusive, que a composição híbrida das disposições de habitus deveriam ser sempre contextualizadas historicamente. $\mathrm{Ou}$ melhor, a dinâmica da fusão de orientações, mais do que historicamente condicionadas, realizar-seia de acordo com a legitimidade e a hierarquia dos valores institucionais em jogo. No caso sociológico de Antônio, destaca-se o peso do projeto familiar aceito docilmente por ele, o valor da educação formal na localidade, bem como o forte compromisso moral entre ele e sua comunidade de origem. Como resultado, tudo

7- Neste sentido, valeria destacar aqui a dimensão prática e cognitiva das disposições de habitus se articulando. Uma forma de ação baseada em um entendimento sobre 0 mundo. foi somado, adaptado e, por fim, articulado a outras experiências de socialização.

Certamente Antonio percebia-se, na ocasião de sua puberdade, diferente de seus colegas e injustamente posicionado na distribuição de direitos sociais; provavelmente esse exercício comparativo aguçou seu interesse em mudar de destino e às dificuldades encontradas respondeu com uma boa vontade cultural contínua. É possível observar em Antonio certa postura dócil frente às atividades e práticas de cultura prestigiadas pelas frações da elite (BOURDIEU, 1979). Desde o ano de sua formatura no ensino médio, em 1992, praticamente nunca parou de investir nos estudos: concluiu o magistério (1994), um curso de inglês (1996-2000), frequentou um cursinho para vestibular (1999), ingressou na universidade (2000) e agora acabou de finalizar sua pós-graduação (2010). Afırma todo tempo que não quer compromisso com mulheres, não quer ter filhos e o investimento em seu futuro traduz-se numa escolha sempre explícita pelo campo cultural. Como grande parte dos trânsfugas de classe, Antonio ainda hoje sente e expressa a ambiguidade de estar no meio de uma travessia. Sua posição social é ambivalente, pois está no meio do caminho, em uma encruzilhada; está atravessado por sentimentos contraditórios de modelar-se à semelhança dos grupos hierarquicamente superiores, ao mesmo tempo percebendo não ter chegado lá. É notável ainda em seu discurso a rejeição a um estilo de vida restrito à família, trabalho, filhos e velhice. Tem sede de conhecer o mundo, cidades famosas, pessoas diferentes e seus contatos fora do estado ou do país são troféus bem cuidados. A necessidade e o gosto pela cultura local e mundializada como imagem e semelhança são elementos construtores de uma identidade social e pessoal.

Operacionalmente, a dimensão prática e cognitiva pode ser identificada nas escolhas que faz. Na experiência estética, é possível observar que, na composição de suas práticas de cultura, não existe a centralidade das disposições 
escolares, ainda que seja professor e escritor; na análise de seu comportamento e preferências de gosto, não seria possível circunscrevê-lo em uma origem popular e ou indígena; o gosto cultural de Antonio é a síntese de todos esses atravessamentos. A casa onde mora é uma fusão das referências a que tem acesso. Uma composição de temporalidades e de gosto expressam a realidade de que faz parte. Uma TV LG convive com um artesanato indígena; um sofá e uma rede dividem igualmente sua atenção nos momentos de repouso; utensílios de alumínio e ou plástico, dourados ou de cores tropicais confundem-se numa composição particular. Cartazes de eventos realizados por ele, bem como banners em que sua figura divide espaço com a Torre Eiffel traduzem um sentimento atravessado por experiências culturais locais e mundializadas (ORTIZ, 2000).

$\mathrm{Na}$ dimensão do trabalho, desde a infância, Antonio precisou participar do roçado, entre outras atividades de coleta ou trabalho braçal, e mesmo como professor foi responsável por várias atividades. 0 ambiente por onde circula propicia a fragmentação e a disposição em direção a um habitus cujo modus operandi é o da fusão e o da circulação por referências e práticas laborais diversas, o que enseja novas articulações, sínteses e perspectivas disposicionais heterogêneas. Decerto, talento, determinação pessoal, em associação a valores e a uma flexibilidade de estrutura social local foram fatores capazes de construir as condições de possibilidade para realizações desta natureza.

No que se refere à dimensão ética, Antonio parece ter consciência do valor de sua boa vontade cultural. Sabe que quanto mais se estuda, mais se torna reconhecido, notável, distinto e, mais que tudo, livre dos constrangimentos financeiros e de criação. Mais do que isso, garante-se o direito a uma singularidade. Ademais, valeria salientar, suas escolhas não são determinações do destino, tampouco são inatas; parecem estar mais próximas de estratégias ou mesmo ser táticas de avaliação de um campo de forças. Pertencente a uma localidade em que se aposta num modelo liberal de sucesso social e individual, sensível às armadilhas de instabilidade dele constitutivas, Antonio parece desenvolver um sentimento de inconsistência posicional, tal como descrito por Arteaga e Martuccelli (2012, p. 293). Ou seja, a especificidade da estrutura local, sua instabilidade e vulnerabilidade, devido aos grandes reveses dos ciclos econômicos de crescimento seguido de depressão, proporcionam um indivíduo aberto a aproveitar as chances de mobilidade apresentadas. Num ambiente estruturalmente movediço, em que as posições sociais alcançadas podem vacilar devido às oscilações econômicas, como é o caso da região em que Antonio se socializou, é possível observar uma configuração favorável a processos de individuação, associada a uma rede de relações, contatos ou mutualismo. No relato de Antonio, nota-se como ele soube/sabe aproveitar as oportunidades que lhe foram/são apresentadas. Antonio também revela empiricamente sua facilidade em converter capital cultural em capital econômico e, sobretudo, demonstra a arte de transformá-los em capital simbólico. Vínculos de amizade ou laços profissionais, uma autêntica rede de contatos, sempre lhe serviram como instrumento para capitalizar esforços, para tecer visivelmente um capital de reconhecimento. Tendo facilidade de se associar seja com o universo culto da cidade, professores e pesquisadores locais ou externos, seja com a população de antigos moradores da região, Antonio constrói conexões de muitos matizes, fazendo uso de todas elas quando necessário. Ele apresenta certo sentido de oportunismo, astúcia ou jogo de cintura, enfım certa disposição ou predisposição para garantir uma situação e ou posição até então conquistada, uma espécie de capital social em constante construção (BOURDIEU, 1998; MARTUCCELLI, 2010).

No tocante à dimensão religiosa, valeria assinalar que seu protagonismo não acaba na esfera de realizações de ordem material. Antonio também é visto, por muitos, como um mensageiro de benefícios espirituais. Se não 
bastasse seu prestígio no mundo das ideias profanas e acadêmicas, Antonio parece ter, mesmo que não queira, um destaque na esfera religiosa. Católico com fé e leitor da Bíblia, embora não praticante, em várias ocasiões, foi levado a intermediar a esfera terrena com a espiritual. Talvez seja sua condição de escolhido pelo Menino Jesus, como dizem seus familiares. Antonio, para muitos, é um indivíduo abençoado. Segundo seu relato, já participou de várias situações de interlocução com entidades espirituais. Apropriando-se de e seguindo prescrições de pajés ou de entidades imateriais, foi capaz de livrar muitas famílias de circunstâncias misteriosas, em que o peso dos mortos ainda se fazia sentir. Durante algum tempo, também foi portador da palavra de entes incorpóreos, bem como fez uso de suas mensagens para tratar de dificuldades de saúde e de problemas de membros da comunidade.

Antonio admite fazer preces todas as noites, seguindo o aprendizado de sua mãe, ainda que não frequente o culto católico com assiduidade. Sua família é um exemplo de pluralidade religiosa, oportunizando a convivência e o estímulo para diferentes e imponderáveis articulações de distintas orientações religiosas. Assim sendo, suas experiências espirituais não se opõem a outros credos nem às outras crenças convencionalmente racionais e lógicas. Ao contrário, Antonio não se imagina fazendo uso de referências dissonantes, nem mesmo se poderia atribuir esse sentido às interpretações que faz sobre realizações e práticas no campo religioso. Segue vivendo. Sua experiência desde pequeno foi traduzida por fusões de representações derivadas de matrizes culturais diversas de maneira quase naturalizada, visto que aprendeu a respeitá-las e amalgamá-las, sempre quando em contato com a situações embaraçosas. As aproximações, articulações e ou os ajustes simbólicos parecem ser constitutivos de seu processo socializador: esse é o modus operandi de seu habitus. Os desafios estão lá, as articulações podem possuir várias direções, levando a configurações de sentido imponderáveis, porém nunca arbitrárias. As articulações fazem crer, aliviam tensões, auxiliam na travessia e, portanto, são vividas enquanto reais e evidentes.

Talvez se pudesse insistir na compreensão de suas escolhas e realizações a partir de um feixe de condicionamentos socio-históricos. Aliados a esse espaço-tempo, é necessário lembrar o estímulo doméstico, certa estabilidade econômica, bem como uma inquietação pessoal. Ademais, a frequência a uma escola de qualidade e suas incitações, além do contato com modelos identitários de sucesso também não poderiam deixar de serem citados. Esses são fatores de ordem e natureza variadas, mas que, agindo de maneira interdependente parecem ser responsáveis pelo rumo que sua vida tomou. Aspectos que agiram na construção de um sistema de acondicionamentos que o predispôs a se orientar, valendo-se de experiências díspares, contudo capazes de instrumentalizá-lo para a vida. Condições particulares de socialização que circunscreveram maneiras específicas de compor uma individuação, um modus vivendi sui generis. Enfım, um modus vivendi movido pela articulação de disposições de cultura favoráveis à realização de sua individuação.

Por fim, sociologicamente, seu singular perfil não deixa de ser curioso: foi sendo conquistado lentamente, a partir do enfrentamento de muitos desafios e constrangimentos. No decorrer de seu percurso, foi somando aprendizados, pulando obstáculos, desviando-se, encantando-se ou se debatendo com ensinamentos, sempre articulando disposições e orientações de cultura de naturezas diversas. A vivência de tantas experiências de socialização parece ampliar suas opções, ao mesmo tempo em que lhe possibilita a construção de uma identidade, uma individuação em processo. A forma como testa sua vocação nesta ou naquela atividade não lhe confere muita dificuldade ou angústia. Transita por todas, às vezes se dá bem, continua seguindo experimentos, atravessa fronteiras de gosto e, por fim, constrói um sistema de 
princípios sujeito a constantes reformulações. Está sendo socializado em condições específicas e precisa fazer valer o modus operandi da fusão e hibridação de disposições de habitus.

Em outras palavras, estaria em seu habitus essa disposição involuntária, aventureira, de aproveitar as oportunidades. Tudo leva a crer que, numa estratégia (BOURDIEU, 1979) ou numa tática (DE CERTEAU, 2002), Antonio sabe tirar proveito de conhecimentos e conhecidos, sabe articular sensibilidade e desejos pessoais num contexto sociotemporal propício para tal. Sua biografia de vida revelou a trama de uma estrutura, de uma história cultural, bem como valores que, em conjunto, sedimentaram experiências dissonantes.

\section{Considerações finais}

Se, na tentativa de finalizar esta reflexão, se perguntasse se Antônio é um sujeito socializado na Amazônia, decerto entrar-se-ia em uma discussão parcial. De fato, ele é um amazônida, mas um amazônida que compôs seu sistema de orientações (habitus) a partir de uma multiplicidade de referências culturais. Nesse sentido, suas disposições de cultura possuiriam muito da alma amazonense, da essência do paraense e/ou do espírito santareno. Contudo, Antonio não é só isso; é um pouco de tudo isso e muito mais. Nasceu e vive num espaçotempo em que a fusão e o atravessamento de influências são inexoráveis e, até certo ponto, imponderáveis (ORTIZ, 2000). A dinâmica das configurações locais é intensa. As diligentes frentes migratórias, as comunicações virtuais impõem um ritmo acentuado de trocas culturais. Instabilidade e riscos caminham juntos nesse processo aberto de construção do social, produzindo um contexto favorável à emergência de híbridas disposições de habitus.

Vale ressaltar ainda que as noções de reconhecimento e escolha trazidas como eixos da vida de Antonio permitiram visualizar o diálogo com a teoria do habitus enquanto um social subjetivado ${ }^{8}$. Ambas as noções auxiliam a imaginar analiticamente a ideia de confıguração no interior da qual as relações sociais vividas encerram um sentido, uma história. Isto posto, talvez não seja demasiado afirmar ou mesmo apostar que tais noções poderiam ser úteis para outras análises de casos de trajetórias singulares, outras experiências de vida, explicitando a dialética e a tensa correspondência entre indivíduo e sociedade. Elas são capazes de revelar as relações de interdependência entre os processos da socialização e da individuação; evidenciam que se perceber como sujeito/ pessoa é indissociável do reconhecimento que se recebe dos outros. As escolhas que fazemos resultam de um contínuo, são produtos de uma intersubjetividade. As apostas individuais respondem a certa intuição de que, para se ver reconhecido, é necessário tecer um terreno favorável, considerar uma ambiência, uma via, um percurso viável. A escolarização e seus efeitos nos rumos profissionais foram uma delas na trajetória de Antonio. A educação formal e escolar revelam-se como fenômenos, como práticas que evidenciam um contexto histórico, corroboram valores que permeiam vidas individuais, que estruturam a desigual distribuição de poderes.

Em síntese, seguindo ensinamentos há muito difundidos acerca das relações de interdependência entre indivíduo e sociedade, bem como acompanhando o movimento das inflexões sociológicas contemporâneas, o esforço empreendido nessas reflexões ensejou apresentar uma contribuição à teoria da socialização. Pensar relacionalmente os fenômenos sociais nas suas manifestações estruturais ou subjetivas foi um desafio. Abandonando o entendimento de que haveria uma correspondência estreita entre ator e sistema, estruturas mentais e sociais, buscou-se investigar a origem efetiva da vida social, os

8- "Falar de habitus é colocar que o individual, e mesmo o pessoal, é subjetivo, é social, é coletivo. 0 habitus é uma subjetividade socializada" (BOURDIEU, 1992, p. 101, tradução nossa). 
sentidos e as razões históricas e estruturais que levariam os indivíduos a articular referências sociais distintas. Nesse sentido, optou-se por uma perspectiva que não se ocupou exclusivamente nem do sistema nem do ator, mas do intermeio tecido entre os dois, ou seja, a história e os sentidos.

Por fim, a experiência de Antônio pôde retratar o imponderável processo de articulação de distintas disposições de cultura. Observou-se que no interior dessas experiências, apesar de condicionadas por marcadores sociais como origem social e local de moradia, abriram-se diferentes alternativas. A diversidade de orientações a que se teve acesso, embora plurais, foram sempre permeadas por tessituras valorativas verticais. A escolha pela escolarização na busca de um reconhecimento foi construída ao longo de um percurso, a partir de uma singular percepção de interesses em disputa. Detectou-se, pois, empiricamente, as condições de possibilidade de um espaço-tempo em que a articulação de disposições de cultura fez-se indispensável e desejável, na medida em que circunstâncias sociais assim o exigiram. Dessa forma, em condição de modernidade, crê-se que a noção de hibridismo se fez oportuna e traz uma contribuição à teoria disposicionalista do habitus.

\section{Referências}

ARNOLDI, Eliana. Leitura e escrita de professores: socializações e práticas profissionais. 2014. 217 p. Dissertação (Mestrado em Sociologia da Educação) - Faculdade de Educação da Universidade de São Paulo, São Paulo, 2014.

ARTEAGA, Catalina A.; MARTUCCELLI, Danilo. Neoliberalismo, corporativismo y experiências posicionales: Ios casos del Chile y Francia. Revista Mexicana de Sociologia, México, DF, v. 74, n. 2, p. 275-302, abr./jun. 2012. Disponível em: <www.revistas. unam.mx/index. php/rms/article/download/31204/28893>. Acesso em: 30 set. 2013.

BOURDIEU, Pierre. La distinction: critique social du jugement. Paris: Minuit, 1979.

BOURDIEU, Pierre. Meditações Pascalianas, Oeiras, Ed. Celta, 1998.

BOURDIEU, Pierre. Pierre Bourdieu avec Löic Wacquant: réponses. Paris: Seuil, 1992.

BOURDIEU, Pierre; CHARTIER, Roger. 0 sociólogo e o historiador. Belo Horizonte, Autêntica, 2011.

CERTEAU, Michel de. A invenção do cotidiano: artes de fazer. Petrópolis: Vozes, 2002.

DAYRELL, Juarez. Ser alguém na vida: juventude, escola e a busca por reconhecimento. Belo Horzonte: UFMG, 2014. Texto de circulação restrita.

GARCIA-CANCLINI, Nestor. Culturas híbridas. São Paulo: Edusp, 1997.

GARCIA-CANCLINI, Nestor. Noticias recientes sobre la hibridación. Trans: Revista Transcultural de Música, n. 7, 2003. Texto presentado como conferencia del profesor invitado en el VI Congreso de la SibE, celebrado en Faro en julio de 2000.

GOMES, Elias E. Ensaios etnográficos sobre a socialização da juventude para a sexualidade e a fé: "vem, você vai gostar!". 2010. 190 p. Dissertação (Mestrado em Sociologia da Educação) - Faculdade de Educação da Universidade de São Paulo, São Paulo, 2010.

GUÉGUEN, Haud; MALOCHET, Guillaume. Les théories de la reconnaissance. Paris: La Découverte, 2012. Repères.

HONNETH, Axel. La lutte pour la reconnaissance. Revue Sicences Humanines, Paris, n. 172, juin 2006. Entretien avec Axel Honneth.

LAHIRE, Bernard. A cultura dos indivíduos. Porto Alegre: Artmed. 2006. 
LAHIRE, Bernard. Retratos sociológicos: disposições e variações individuais. Porto Alegre: Artes Médicas, 2004b.

LAHIRE, Bernard. Trajetória acadêmica e pensamento sociológico: entrevista com Bernard Lahire. Educação e Pesquisa, São Paulo, v. 30 n. 2, p. 315-321, maio/ago. 2004a.

MARTUCCELLI, Danilo. Cambio de rumbo: la sociedad a escala del individuo. Santiago de Chile: LOM, 2007.

MARTUCCELLI, Danilo. Existen indivíduos en el Sur? Santiago de Chile: LOM, 2010.

MONTEIRO, Paula. 0 problema do sincretismo. Teoria e Sociedade, Belo Horizonte, n. especial, p.112-119, maio 2003.

NOGUEIRA, Claudio. A abordagem de Bernard Lahire e suas contribuições para a sociologia da educação. Goiânia: Anped, 2013. Texto apresentado para a sessão especial "Estrutura e indivíduo: um debate acerca dos enfoques grupais e individuais na sociologia da educação".

ORTIZ, Renato. 0 próximo e o distante: Japão e modernidade - mundo. São Paulo. Brasiliense, 2000.

REIS, Juliana Batista. Transversalidade nos modos de socialização e individuação: experiências juvenis em rede. 2014. 222 f. Tese (Doutorado em Educação) - Programa de Pós-Graduação da Universidade Federal de Minas Gerais (UFMG), Belo Horizonte, 2014.

SETTON, Maria da Graça Jacintho. A socialização como fenômeno social total: notas introdutórias sobre a teoria do habitus. Revista Brasileira de Educação, Rio de Janeiro, v. 14, n. 41, p. 296-307, maio/ago. 2009a.

SETTON, Maria da Graça Jacintho. A teoria do habitus em Pierre Bourdieu: uma leitura contemporânea. Revista Brasileira de Educação, Rio de Janeiro, n. 20, p. 60-70, maio/ago. 2002.

SETTON, Maria da Graça Jacintho. Relatório final de pesquisa. São Paulo: Fapesp, 2014.

SETTON, Maria da Graça Jacintho. Socialização e cultura: ensaios teóricos. São Paulo: AnnaBlume, 2012.

SETTON, Maria da Graça Jacintho; SPOSITO, Marilia Pontes. Como os indivíduos se tornam indivíduos? Entrevista com Danilo Martuccelli. Educação e Pesquisa, São Paulo, v. 39, n. 1, p. 247-267, jan./mar. 2013.

Recebido em: 15.10.2014

Aprovado em: 24.03.2015

Maria da Graça Jacintho Setton é professora associada livre-docente no Departamento de Filosofia e Ciências da Educação, área de sociologia, da Faculdade de Educação da Universidade de São Paulo. 